\title{
Trajectories Of Zooplankton Recovery In The Little Rock Lake Whole-Lake Acidification Experiment
}

Thomas M. Frost

Janet M. Fisher

Jennifer L. Klug

Fairfield University, jklug@fairfield.edu

Shelley E. Arnott

Pamela K. Montz

Follow this and additional works at: https://digitalcommons.fairfield.edu/biology-facultypubs

Copyright 2006 Ecological Society of America

Final publisher pdf has been archived here with permission from the copyright holder.

\section{Peer Reviewed}

\section{Repository Citation}

Frost, Thomas M.; Fisher, Janet M.; Klug, Jennifer L.; Arnott, Shelley E.; and Montz, Pamela K., "Trajectories Of Zooplankton Recovery In The Little Rock Lake Whole-Lake Acidification Experiment" (2006). Biology Faculty Publications. 40.

https://digitalcommons.fairfield.edu/biology-facultypubs/40

\section{Published Citation}

Frost, Thomas M., Janet M. Fischer, Jennifer L. Klug, Shelley E. Arnott, and Pamela K. Montz. "Trajectories Of Zooplankton Recovery In The Little Rock Lake Whole-Lake Acidification Experiment." Ecological Applications 16, no. 1 (2006): 353-367.

This item has been accepted for inclusion in DigitalCommons@Fairfield by an authorized administrator of DigitalCommons@Fairfield. It is brought to you by DigitalCommons@Fairfield with permission from the rightsholder(s) and is protected by copyright and/or related rights. You are free to use this item in any way that is permitted by the copyright and related rights legislation that applies to your use. For other uses, you need to obtain permission from the rights-holder(s) directly, unless additional rights are indicated by a Creative Commons license in the record and/or on the work itself. For more information, please contact digitalcommons@fairfield.edu. 


\section{WILEY}

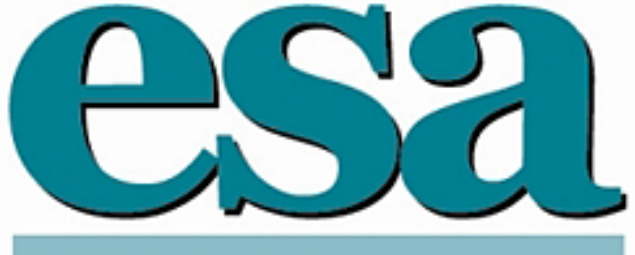

Trajectories of Zooplankton Recovery in the Little Rock Lake Whole-Lake Acidification Experiment

Author(s): Thomas M. Frost, Janet M. Fischer, Jennifer L. Klug, Shelley E. Arnott and Pamela K. Montz

Source: Ecological Applications, Vol. 16, No. 1 (Feb., 2006), pp. 353-367

Published by: Wiley on behalf of the Ecological Society of America

Stable URL: http://www.jstor.org/stable/40061804

Accessed: 31-08-2017 17:08 UTC

JSTOR is a not-for-profit service that helps scholars, researchers, and students discover, use, and build upon a wide range of content in a trusted digital archive. We use information technology and tools to increase productivity and facilitate new forms of scholarship. For more information about JSTOR, please contact support@jstor.org.

Your use of the JSTOR archive indicates your acceptance of the Terms \& Conditions of Use, available at http://about.jstor.org/terms

Wiley, Ecological Society of America are collaborating with JSTOR to digitize, preserve and extend access to Ecological Applications 


\title{
TRAJECTORIES OF ZOOPLANKTON RECOVERY IN THE LITTLE ROCK LAKE WHOLE-LAKE ACIDIFICATION EXPERIMENT
}

\author{
Thomas M. Frost, ${ }^{1,5}$ Janet M. Fischer, ${ }^{2,6}$ Jennifer L. Klug, ${ }^{3}$ Shelley E. Arnott, \\ ${ }^{4}$ AND PAMela K. MONTZ ${ }^{1}$ \\ ${ }^{1}$ Trout Lake Station, Center for Limnology, University of Wisconsin, 10810 County Highway N, \\ Boulder Junction, Wisconsin 54512 USA \\ ${ }^{2}$ Department of Biology, Franklin and Marshall College, Lancaster, Pennsylvania 17604 USA \\ ${ }^{3}$ Biology Department, Fairfield University, Fairfield, Connecticut 06824 USA \\ ${ }^{4}$ Department of Biology, Queen's University, Kingston, Ontario K7L 3N6 Canada
}

\begin{abstract}
Understanding the factors that affect biological recovery from environmental stressors such as acidification is an important challenge in ecology. Here we report on zooplankton community recovery following the experimental acidification of Little Rock Lake, Wisconsin, USA. One decade following cessation of acid additions to the northern basin of Little Rock Lake (LRL), recovery of the zooplankton community was complete. Approximately $40 \%$ of zooplankton species in the lake exhibited a recovery lag in which biological recovery to reference basin levels was delayed by 1-6 $\mathrm{yr}$ after $\mathrm{pH}$ recovered to the level at which the species originally responded. Delays in recovery such as those we observed in LRL may be attributable to "biological resistance" wherein establishment of viable populations of key acid-sensitive species following water quality improvements is prevented by other components of the community that thrived during acidification. Indeed, we observed that the recovery of species that thrived during acidification tended to precede recovery of species that declined during acidification. In addition, correspondence analysis indicated that the zooplankton community followed different pathways during acidification and recovery, suggesting that there is substantial hysteresis in zooplankton recovery from acidification. By providing an example of a relatively rapid recovery from short-term acidification, zooplankton community recovery from experimental acidification in LRL generally reinforces the positive outlook for recovery reported for other acidified lakes.
\end{abstract}

Key words: acidification; biological resistance; $\mathrm{pH}$ stress; recovery; resilience; whole-lake experiment; zooplankton.

\section{INTRODUCTION}

Acidic deposition has been recognized as a major environmental stress in aquatic ecosystems over the last 25 years (Stoddard et al. 1999, Driscoll et al. 2001). Legislative actions to reduce rates of sulfur dioxide emissions in North America and Europe were motivated by concern about the ecological impacts of acidic deposition, and consequently, sulfur dioxide emissions were significantly reduced in the 1980 s and 1990 s (Stoddard et al. 1999, Driscoll et al. 2001). Chemical recovery has been reported for some North American aquatic ecosystems that had been anthropogenically acidified (Stoddard et al. 1999, Driscoll et al. 2003, Keller et al. 2003). Improvements in water quality have also been noted in other locations, including Scandinavia (Evans et al. 2001, Skjelkvåle et al. 2001, Forsius

Manuscript received 2 December 2004; revised 5 May 2005; accepted 17 May 2005. Corresponding Editor: J. J. Elser.

$s$ Published posthumously. This paper is dedicated to the memory of Thomas M. Frost (1950-2000): scientist, mentor, and friend. We remember our conversations with Tom about Little Rock Lake's "acid champs" and "acid chumps" with great fondness.

${ }^{6}$ Corresponding author. E-mail: jfischer@fandm.edu et al. 2003) and eastern Europe (Evans and Monteith 2001, Evans et al. 2001). However, it is important to note that chemical recovery has not occurred in some locations (e.g., the Adirondacks of North America, Germany, and parts of southeastern Canada and the United Kingdom) and is not expected in some impacted systems unless further reductions in emissions are legislated (Evans et al. 2001, Henriksen et al. 2002, Driscoll et al. 2003, Jeffries et al. 2003a, b, Keller et al. 2003).

Because biological recovery is a major goal of legislative action, monitoring programs focused on aquatic biota have been undertaken in a variety of locations (Locke and Sprules 1994, Arnott et al. 2001, Walseng et al. 2001, Keller et al. 2002, Nilssen and Waeervagen 2002, Findlay 2003, Holt and Yan 2003, Snucins 2003, Vrba et al. 2003, Waeervagen and Nilssen 2003). These high-quality long-term data sets are critical for addressing questions about the rate and trajectory of recovery (Parr et al. 2003). Several studies have suggested that biological recovery may be delayed compared to chemical recovery (Driscoll et al. 2001, Dixit et al. 2002, Yan et al. 2003). Furthermore, the length of the lag for biological recovery may vary substan- 
tially among aquatic ecosystems. For example, Driscoll et al. (2003) hypothesized that the lag between chemical recovery and recovery of invertebrates in acidified streams and lakes may range from three to 10 years. Here, we report on variation in the recovery trajectories of zooplankton following the experimental acidification of Little Rock Lake (LRL), Wisconsin, USA.

Freshwater zooplankton are well-suited to investigation of biological recovery from acidification because they are relatively easy to monitor and have been studied in a variety of geographic locations that are recovering from acidification (Keller and Yan 1998). Although recovery can proceed rapidly in some lakes, most studies indicate that zooplankton recovery requires about a decade (Keller and Yan 1998). A wide variety of metrics have been used to evaluate zooplankton recovery from acidification, including univariate measures of indicator species abundances, aggregate measures of zooplankton species richness and diversity, and multivariate metrics of community composition (Yan et al. 1996). Several studies indicate that multivariate measures of community composition are sensitive indicators of recovery (Yan et al. 1996, Holt and Yan 2003). For example, a multivariate index of zooplankton species composition provides evidence of recovery in nine acidic lakes in Killarney Park, Ontario, Canada, where $\mathrm{pH}$ had risen above 6 , whereas zooplankton species richness did not change during the same time period (Holt and Yan 2003). These studies underscore the value of quantifying changes in species composition, in addition to coarser metrics of community response.

Detailed analyses of recovery of zooplankton species composition following water quality improvements have potential to reveal variation in recovery rates for different components of the zooplankton community in a given lake. For example, Arnott et al.'s (2001) analysis of recovery of plankton in Swan Lake, Ontario, Canada, supports the hypothesis that recovery rates differ between taxonomic groups (e.g., rotifers vs. crustaceans). The rate of recovery to pre-acidified conditions may also be influenced by the nature of the initial response to acidification (e.g., whether the species declined or thrived under acidified conditions). During the first five years of recovery of Little Rock Lake from experimental acid addition, several species that had increased during acidification returned to pre-acidified levels whereas the recovery of some species that declined during acidification was delayed (Frost et al. 1998). Thus, patterns of biological recovery can be complex and mechanisms driving these patterns remain poorly understood.

The goal of our study was to summarize patterns of zooplankton recovery following a whole-lake acidification experiment conducted in Little Rock Lake, Wisconsin. Because the choice of metric may affect our perception of recovery, we compared recovery trajectories for highly aggregated community metrics (e.g., total zooplankton biomass) and population level metrics (e.g., biomass of individual species). We also focused on the role of biological factors that may affect recovery. For example, we compared recovery trajectories for species that were negatively affected by acidification ("acid chumps") and species that thrived under acidic conditions ("acid champs"). Our study represents an interesting comparison to other recent studies examining zooplankton recovery from acid rain (Arnott et al. 2001, Holt and Yan 2003). The design of the Little Rock Lake experiment included pre-acidification data and parallel monitoring of a closely matched reference system. These features are typically lacking in studies of anthropogenic acidification due to historical and/or logistic reasons. Overall, we believe that the ability to follow zooplankton community trajectories in Little Rock Lake for 16 years, including a full cycle of response and recovery (see Mittelbach et al. 1995), provided a unique opportunity to gain insights about ecological resilience to acidification.

\section{Methods}

\section{Whole-lake experiment}

In 1984, the two basins of Little Rock Lake, a bilobed seepage lake located in northern Wisconsin, USA, were separated using a vinyl curtain. Following a year of baseline data collection, sulfuric acid was added to the northern basin (hereafter, acidified basin). The pH of the acidified basin was decreased sequentially to three target pH levels each maintained for two years: 5.6 (1985-1986), 5.1 (1987-1988), and 4.7 (1989-1990). The recovery phase began in 1991 when all acid additions ceased and the acidified basin was allowed to recover naturally. Data collection was completed in 2000. Throughout the entire period (1984-2000), the southern basin (hereafter, reference basin) was unmanipulated and served as a reference system for the changes that occurred in the acidified basin.

\section{Sampling methods}

Details of the limnological sampling are summarized here and described in detail elsewhere (Frost and Montz 1988, Brezonik et al. 1993, 2003). From 1984 to 2000 , water samples for chemical analysis were collected from a central station in each basin once every two weeks during the ice-free season and approximately monthly during winter. Here we present only the $\mathrm{pH}$ data, as changes in chemistry during acidification and recovery have been described elsewhere (Brezonik et al. 1993, 2003, Frost et al. 1999, Sampson and Brezonik 2003).

Samples for enumeration of zooplankton were collected with a 33-L Schindler-Patalas trap (53- $\mu \mathrm{m}$ mesh) at the frequency described above for chemical samples. Samples were collected from fixed depths $(0,4$, and 8 $m$ in the acidified basin and 0,4 , and $6 \mathrm{~m}$ in the reference basin) and preserved with $4 \%$ sucrose-buffered 
formalin. With the exception of the surface sample, the middle of the trap was positioned at the target depth. Hypsometrically weighted mean abundances were calculated for each basin. Zooplankton abundance was converted to biomass using length-mass relationships determined directly for Little Rock Lake species or from the literature (Ruttner-Kolisko 1977, Pace and Orcutt 1981, Culver et al. 1985, Yan and Mackie 1987). Copepod nauplii were not identified to species but are included in analyses of total zooplankton biomass, copepod biomass, and the multivariate analyses of changes in community composition. Additional details on zooplankton analyses are provided in Frost and Montz (1988).

Samples for enumeration of large predatory zooplankton (Chaoborus punctipennis, water mites, Epischura lacustris, and Leptodora kindtii) were collected with a $50 \mathrm{~cm}$ diameter, $253-\mu \mathrm{m}$ mesh conical plankton net at a fixed sampling station after dark. Tows were collected approximately once every two weeks during the ice-free season from $0.5 \mathrm{~m}$ above the deepest point of the basin to the surface, except in 1995 when samples were not collected. Samples were preserved with Lugol's iodine. We used unpublished dry masses of Chaoborus punctipennis (Fischer 1994) to transform abundance to biomass. Biomass estimates for water mites, Epischura lacustris, and Leptodora kindtii were calculated using published values (Meyer 1989, Lawrence et al. 1987, and Hawkins and Evans 1979, respectively). Additional details on predatory zooplankton sampling are provided in Sierszen and Frost (1993).

\section{Data analysis}

We evaluated zooplankton community recovery from acidification using a variety of metrics ranging from population level (e.g., biomass of an individual zooplankton species) to taxonomic groups (e.g., rotifer biomass) to highly aggregated community level (e.g., total zooplankton biomass). For each metric, we compared the time series of annual mean values in the acidified basin to the long-term mean and variability for the same metric (i.e., annual means) in the reference basin. Following the approach of Arnott et al. (2001), we used the 10th and 90th percentiles for each metric across all years (1984-2000) to represent variability in the reference basin. We concluded that a species or group of species in the acidified basin responded to acidification if its annual mean biomass was above or below the range of variability in the reference basin during the acidification years. In a few cases in which a species was slightly outside the range for only one year early in the acidification and returned to within the range for several years (e.g., Bosminids in 1986), we did not classify this species as responding to acidification during the first excursion from the reference basin range. We concluded that a species or group of species had recovered from acidification once its annual mean biomass was consistently within the range of variability defined by the 10th and 90 th percentiles of the reference basin data. In the cases of Daphnia parvula and Tropocyclops extensus, we concluded that recovery occurred in 1997 despite subsequent departures from the 10 th and 90th percentiles of the reference basin data because similar dynamics were noted in the reference basin. We recognize that this is a subjective approach guided by statistical principle and intuition, but suggest that it is a good way to assess general patterns in complex long-term data sets like ours. We also compared the timing of chemical and biological recovery for each taxon. Recovery lag was defined as the time delay between chemical recovery (based on return to the mean annual $\mathrm{pH}$ value in the year before the species responded to acidification) and biomass recovery of each species.

To compare trajectories of change in community composition in the acidified basin to community composition in the reference basin, we used correspondence analysis (CA). Correspondence analysis is an ordination method widely used by community ecologists to examine differences in species composition across environmental gradients (Jackson 1993, Gotelli and Ellison 2004). We $\log _{10}(x+1)$-transformed the biomass data, excluded rare species $(<5 \%$ of biomass of their taxonomic group) from the analysis, and calculated CA using SAS (SAS Institute 1996). Large predatory zooplankton (Chaoborus punctipennis, water mites, Epischura lacustris, and Leptodora kindtii) were not included in the analysis due to one year of missing data. We examined correlations between $\mathrm{CA}$ axis scores and pH, secchi depth, and chlorophyll to explore relationships between environmental factors and changes in zooplankton community composition. It is important to note that these analyses were constrained by the data available and all possible environmental drivers were not examined.

\section{Results}

\section{pH pattern}

During the pre-manipulation year (1984), $\mathrm{pH}$ values in the two basins of Little Rock Lake were very similar (Fig. 1a). Sulfuric acid was added to the acidified basin from 1985 to 1990 , causing a stepwise decrease in $\mathrm{pH}$. Beginning in $1991, \mathrm{pH}$ in the acidified basin was allowed to recover. $\mathrm{pH}$ gradually rose until reaching premanipulation levels in 1996 (Fig. 1). pH in the reference basin was variable over the $17-y r$ record but showed no obvious directional trends (Fig. 1a). Comparing mean annual $\mathrm{pH}$ to the range of natural variability in $\mathrm{pH}$ in the reference basin provided a consistent interpretation of recovery. Mean annual $\mathrm{pH}$ in the acidified basin decreased below the range of variability in the reference basin during the first year of acidification (1985) and returned within the range of variability in the reference basin in 1996 (Fig. 1b). 
a) Biweekly time series
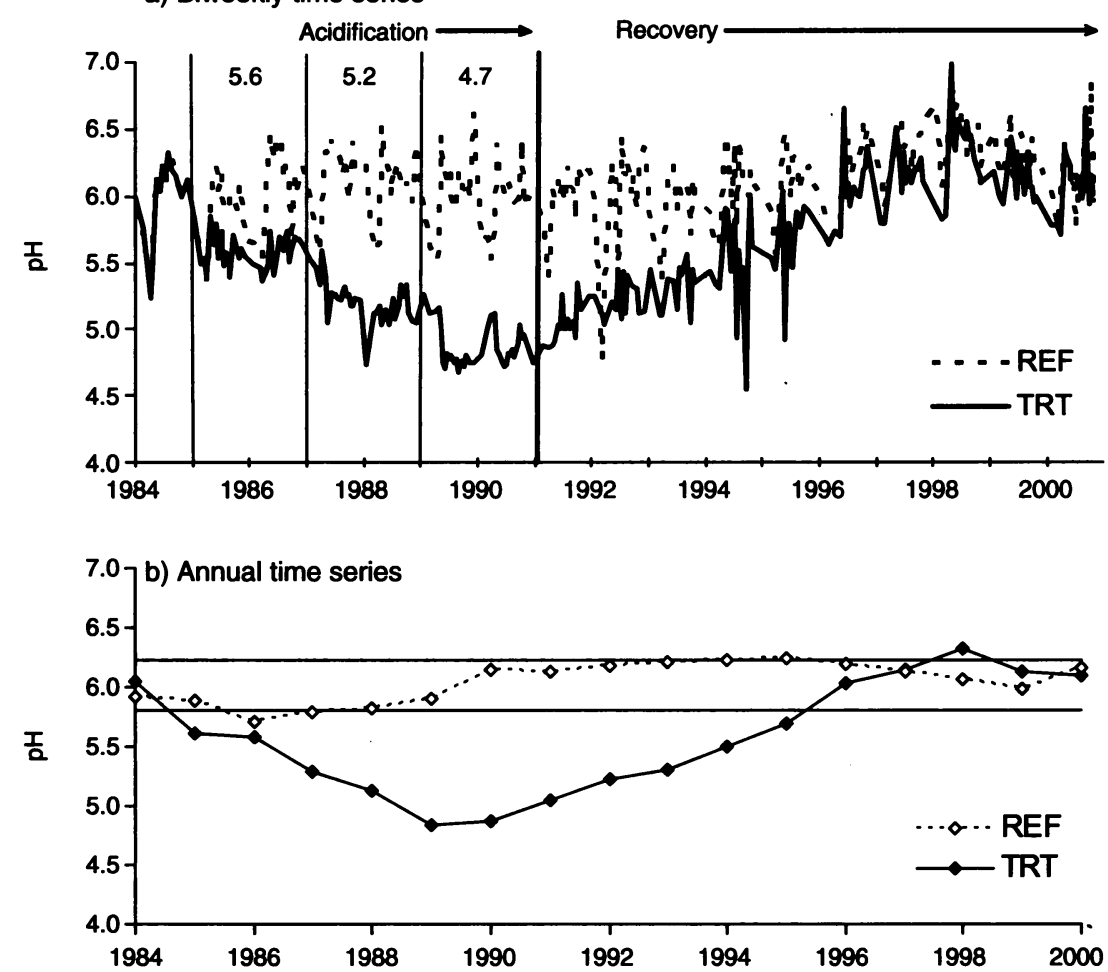

FIG. 1. (a) Time series of $\mathrm{pH}$ values (samples were taken once every two weeks) and (b) annual mean pH in the reference (REF) and treatment (TRT) basins of Little Rock Lake, Wisconsin, USA, from 1984 to 2000. Horizontal solid lines in (b) indicate 10th and 90th percentiles in the reference basin for 1984-2000.

\section{Response and recovery of aggregate groups}

Despite a large decrease in $\mathrm{pH}$, total zooplankton biomass in the acidified basin stayed within the range of variability in the reference basin until the final year of acidification (Fig. 2a). Total zooplankton biomass was lower in 1990 but recovered in 1991. During the rest of the recovery period, total zooplankton biomass was variable but generally stayed within the bounds of the reference envelope (Fig. 2a). Although total rotifer biomass increased during the later stages of acidification, it did not increase above the reference basin envelope until the second year of recovery (1992) and returned to the range of reference basin variability in 1993 (Fig. 2b). Total cladoceran biomass responded to acidification by increasing above the range of variability in the reference basin during the first year of acidification (1985) and decreased to within the reference envelope early in the recovery period (1993) (Fig. 2c). In contrast, total copepod biomass was relatively insensitive to acidification (Fig. 2d). Total copepod biomass stayed within the range of variability in the reference basin until the final year of acidification (1990) and recovered the following year (1991). Copepods dominated the total zooplankton biomass throughout the experiment (Fig. 2a, d).

\section{Response and recovery in species composition}

To assess changes in zooplankton species composition, we used correspondence analysis to compare the community trajectory in the acidified basin to interannual variation (i.e., the cloud of points) in the reference basin. When all species (except large predatory zooplankton) were included in the analysis, dramatic changes in the acidified basin zooplankton assemblage were noted as early as 1986 when the community began to move to the right along CA axis 1 (Fig. 3a, b). The acidified basin community changed to a more acidophilic composition during 1987-1991. However, a recovery trajectory began soon after acidification ended. By 1994-1995, community composition in the acidified basin was similar to the reference basin. In 1996, community composition had essentially returned to an assemblage characteristic of the reference basin. Correspondence analysis axis 1 was negatively correlated with pH ( $n=34, r=-0.77, P=0.0001)$, whereas CA axis 2 was negatively correlated with chlorophyll ( $n=34, r=-0.40, P=0.02$ ). It is interesting to note that significant changes occurred in the reference basin during the study period. The reference basin points with the lowest scores on CA axis 2 correspond to 1996 and 1998-2000. The first two CA axes captured roughly 

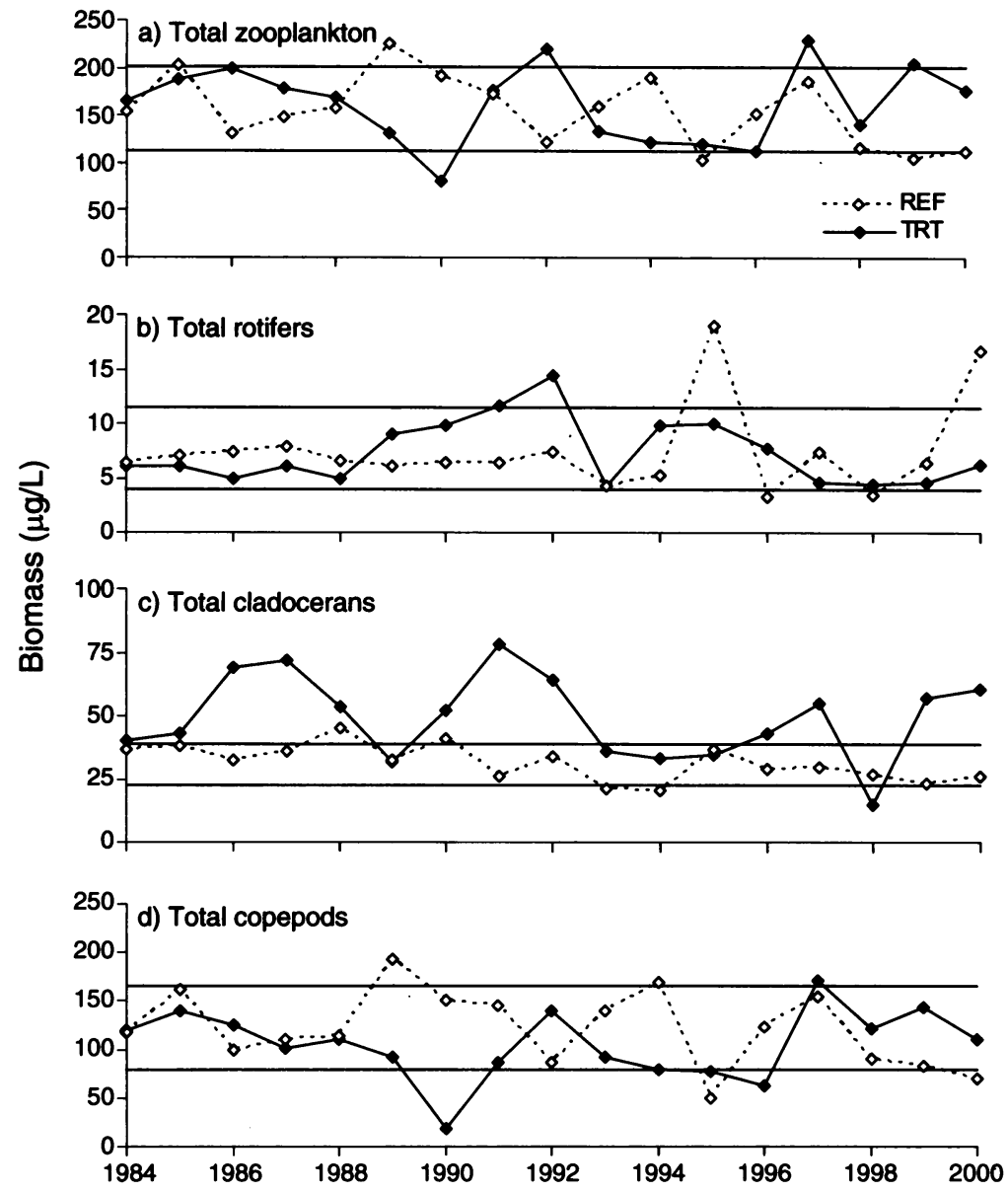

FIG. 2. Annual mean total biomass of (a) zooplankton, (b) rotifers, (c) cladocerans, and (d) copepods in the reference (REF) and treatment (TRT) basins of Little Rock Lake. Horizontal solid lines indicate 10th and 90th percentiles in the reference basin for 1984-2000.

$57 \%$ of the variance $(38.61$ and 17.98 for axes 1 and 2 , respectively).

When only the rotifers were included in the CA, clear changes in the acidified basin assemblage were noted by 1987 , the first year of the second stage of acidification (Fig. 3c, d). Specifically, the acidified basin assemblage moved to the right on CA axis 1 towards a composition characterized by Gastropus hyptopus, Keratella taurocephala, and Synchaeta. Correspondence analysis axis 1 was negatively correlated with $\mathrm{pH}(n=34, r=-0.78, P=0.0001)$. During the recovery period, rotifer community composition in the acidified basin returned to the cloud of reference basin points by 1994. The first two CA axes for the rotifer community captured roughly $54 \%$ of the variance (36.39 and 17.17 for axes 1 and 2, respectively).

The CA for cladocerans revealed substantial variation in the reference basin assemblage during the study period across the first CA axis (Fig. $3 e, f$ ). It is important to note, however, that this pattern does not reflect simple directional change (e.g., from right to left) in the reference basin assemblage. Instead, the trajec- tory in the reference basin was more random. For example, the five reference basin points with negative scores on the first CA axis correspond to 1991, 1994, and 1998-2000. Despite the variation in the reference basin cladoceran assemblage, the acidified basin assemblage exhibited a clear response to acidification in 1986, reflecting a decrease in Daphnia dubia, Holopedium gibberum, and Diaphanosoma and an increase in Daphnia catawba. By 1991, however, the acidified basin assemblage recovered to the broad region defined by the reference basin points. CA axis 1 was positively correlated with secchi depth $(n=34, r=-0.41, P=$ $0.02)$ and negatively correlated with chlorophyll $(n=$ $34, r=-0.35, P=0.04)$, whereas CA axis 2 was negatively correlated with $\mathrm{pH}(n=34, r=-0.49, P$ $=0.003$ ). The first two CA axes for the cladoceran community captured roughly $86 \%$ of the variance (58.09 and 28.23 for axes 1 and 2, respectively).

Similar to cladocerans, the CA for copepods reveals substantial variation in the reference basin assemblage that complicates the interpretation of response and recovery in the acidified basin assemblage (Fig. $3 \mathrm{~g}, \mathrm{~h}$ ). 

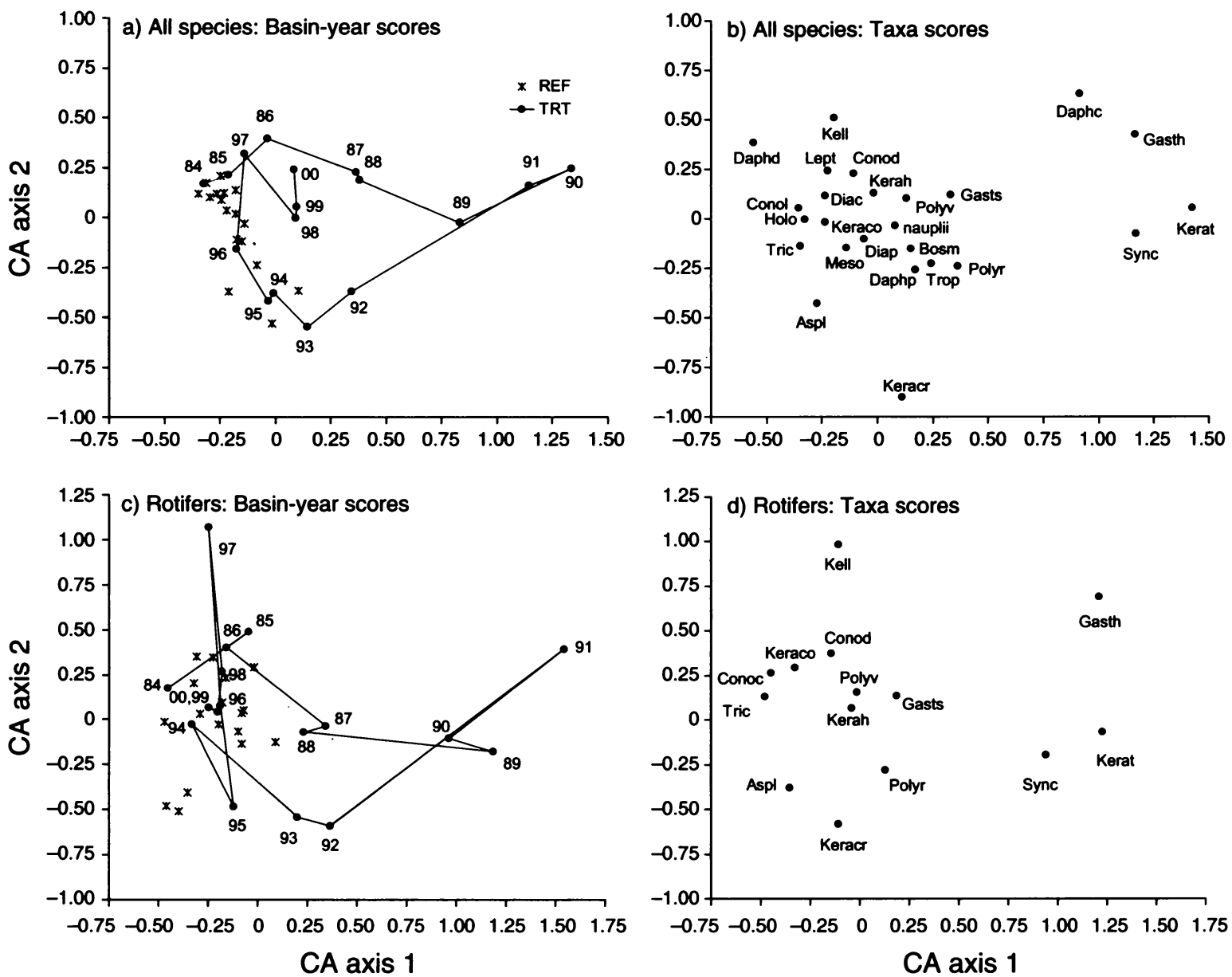

FIG. 3. Scatterplots of the first two axes of the correpondence analysis (CA) for the entire zooplankton community, rotifers, cladocerans, and copepods. Panels in the left columns (a, c, e, g) present the trajectory of years in the reference (REF) and acidified (TRT) basins. Panels on the right $(b, d, f, h)$ show the taxa scores from the ordination of species. Taxa abbreviations are spelled out in Table 1.

Reference basin points that fall outside of the main cloud of points correspond to 1995,1996 , and 19982000. Nonetheless, we interpret the departure of the acidified basin assemblage along the first CA axis from the reference basin cloud beginning in 1988 as a response to acidification. Correspondence analysis axis 1 was negatively correlated with $\mathrm{pH}(n=34, r=$ $-0.62, P=0.0001)$. Movement to the right along CA axis 1 represents an increase in Tropocyclops extensus and a decrease in all other copepod species. A recovery trajectory is evident beginning in 1991 and complete by 1997 . The first two CA axes for the copepod community captured roughly $85 \%$ of the variance $(63.50$ and 21.46 for axes 1 and 2 , respectively).

\section{Response and recovery of individual taxa}

Almost all rotifer and crustacean taxa in the acidified basin decreased or increased outside the range of biomass recorded in the reference basin during the acidification period or during the first two years of the recovery period when pH was still low (Table 1, Figs. 4-
6). All three of the species that did not respond during acidification or early recovery were rotifers (Table 1). Only two species, Asplanchna and Daphnia catawba, responded to the first phase of acidification. Asplanchna decreased in the acidified basin, whereas Daphnia catawba increased. Six species responded to the second phase of acidification, including four species that decreased and two species that increased. During the third phase of the acidification, five species decreased and five species increased. One species (Keratella crassa) decreased during the last phase of the acidification but increased dramatically during recovery. Of the 19 rotifer and crustacean taxa that responded during the acidification period, $84 \%$ had recovered by 1996 when $\mathrm{pH}$ in the acidified basin returned to pre-acidification levels. Interestingly, two taxa that had not responded during the acidification phase of the experiment (bosminids and Gastropus hyptopus) increased sharply during the early phases of recovery (1991-1992) and then quickly returned to the range of the reference basin for the duration of the recovery period (Figs. 4, 5). 

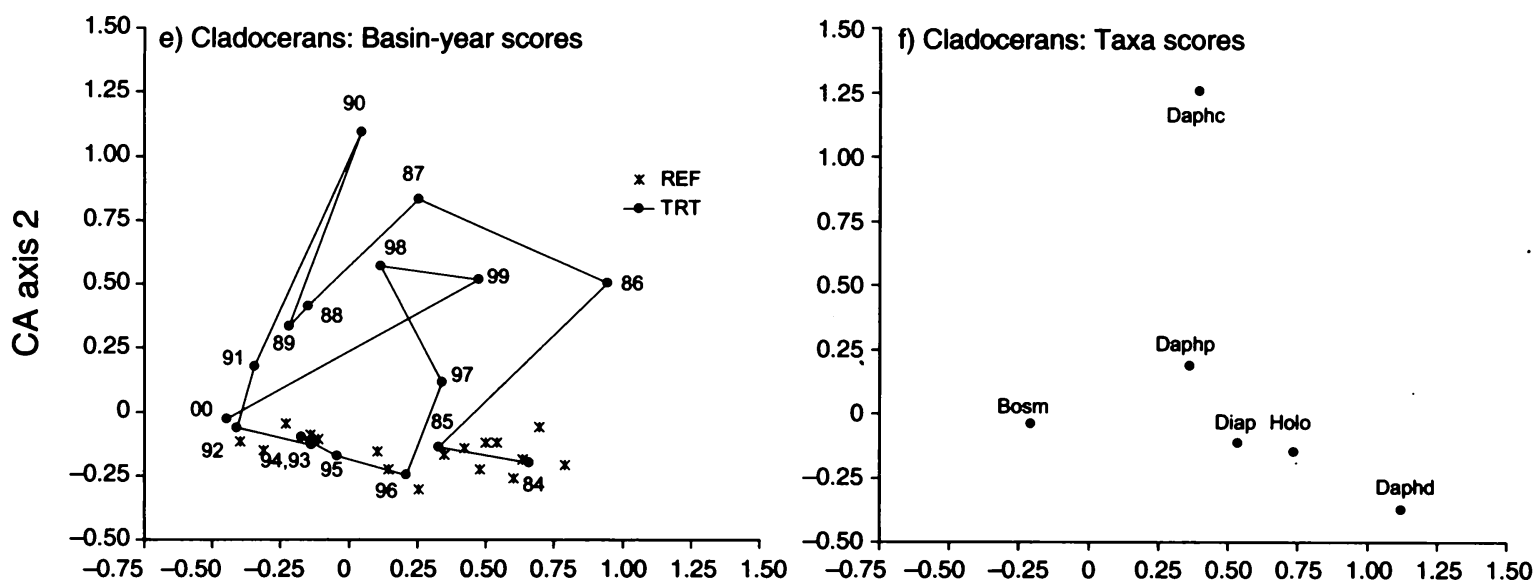

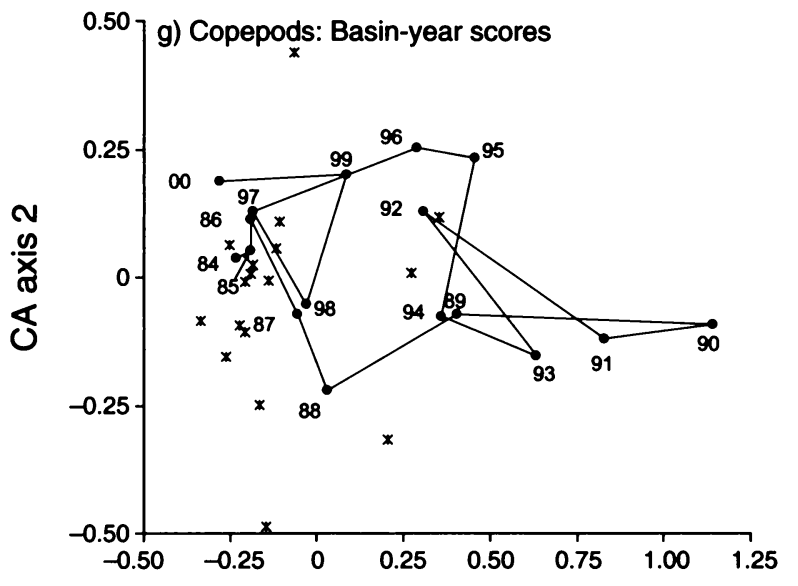

CA axis 1

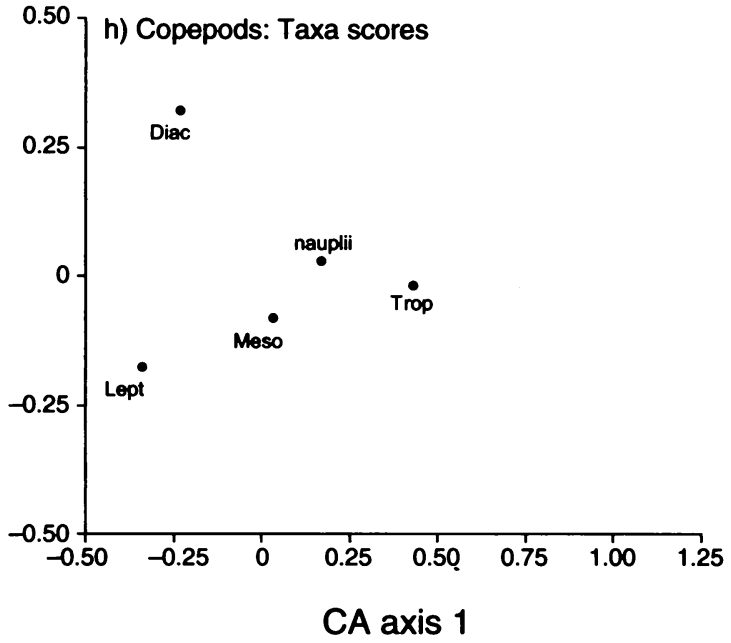

FIG. 3. Continued.

The two dominant invertebrate predators in Little Rock Lake responded differently to acidification (Fig. 7). Water mites were adversely affected by acidification, exhibiting very low abundances during 19891993 (Fig. 7a). We interpret the higher abundances of water mites in 1994 and later years as evidence of recovery. In contrast, the phantom midge, Chaoborus punctipennis, increased with acidification and first departed from the reference basin envelope in 1988 (Fig. 7b). At this time, we noted a decline in total zooplankton biomass (Fig. 2a). However, biomass of Chaoborus decreased to values within the range of variability observed in the reference basin by 1992 (Fig. 7b). Both taxa had high variability in the reference basin throughout the study period.

During the acidification period, nine species were favored by acidification and increased in abundance ("acid champs") and 11 species declined ("acid chumps") (Table 1). This count does not include two species that increased during the recovery phase. In addition, one species (Keratella crassa) decreased in abundance during acidification but increased dramatically during recovery. Due to the complexity of this response, we were unable to classify Keratella crassa as an acid champ or acid chump. In the early part of the recovery phase, acid champs tended to recover more rapidly than acid chumps (Fig. 8a). Recovery of both acid champs and acid chumps was complete by 1997. In general, species recovered at a $\mathrm{pH}$ that was higher than the $\mathrm{pH}$ to which they responded during the acidification period (Fig. 8b). Only three species recovered at $\mathrm{pH}$ levels that were lower than the level at which they responded.

Of the 20 species that responded during the acidification period, eight $(40 \%)$ had a lag in recovery (Table 1). In these cases, there was a time delay between chemical recovery (defined for each species based on $\mathrm{pH}$ levels in the year before the species responded to acidification) and biological recovery. In this group of species with lagged recovery, four were acid champs and four were acid chumps. Recovery lags varied from 1 to $6 \mathrm{yr}$. Mean lag time varied across taxonomic groups. Mean lag times for rotifers, cladocerans, and copepods were $0.78,1$, and $3.25 \mathrm{yr}$, respectively. The two invertebrate predators, mites and Chaoborus punctipennis, exhibited lags of 2 and 0 yr, respectively. 

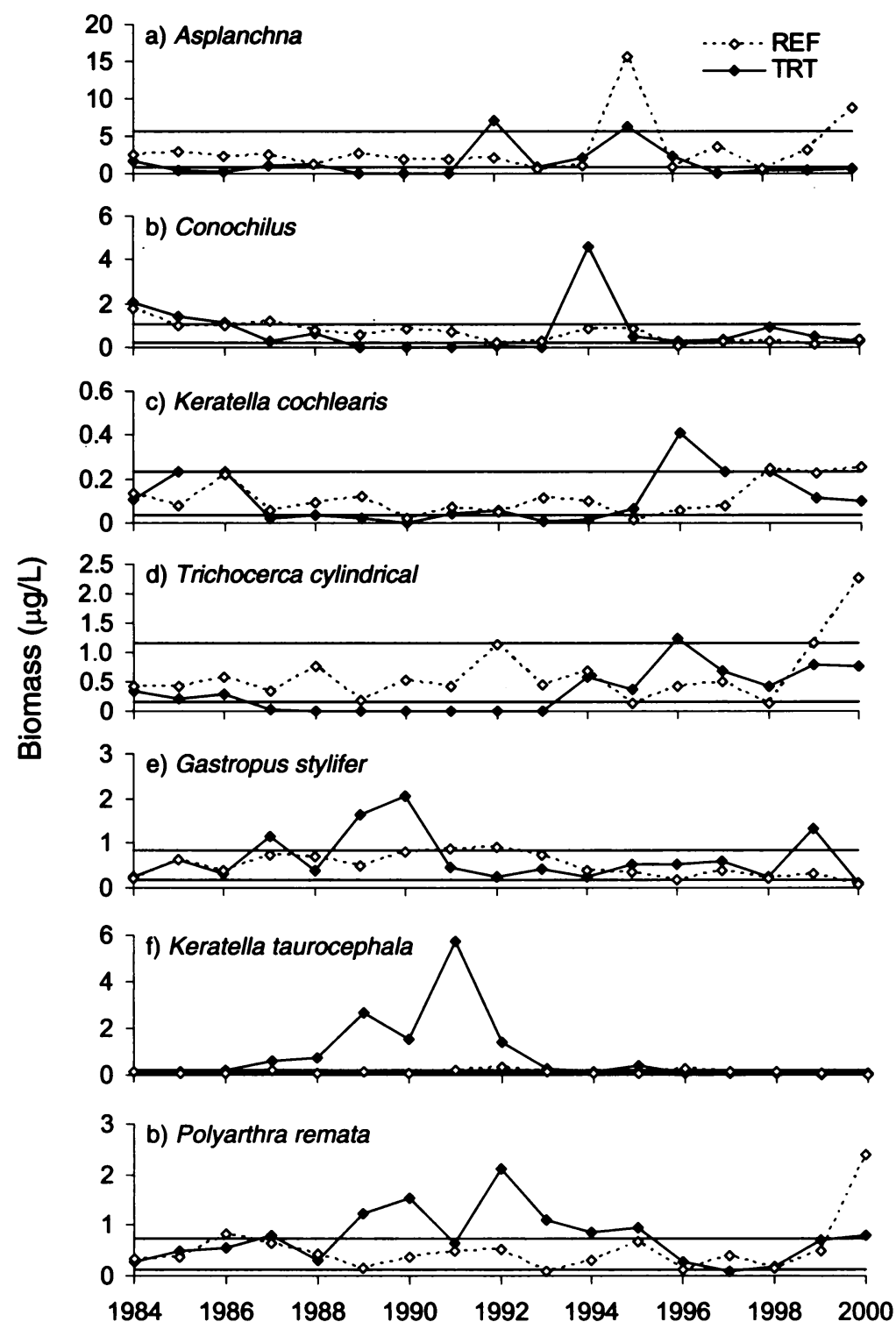

FIG. 4. Annual mean biomass of rotifer species in the reference (REF) and treatment (TRT) basins of Little Rock Lake. Graphs are grouped by the nature of the response to acidification, with decreasing species first, increasing species second, and species with more complex responses or no response last. Horizontal solid lines indicate 10th and 90 th percentiles in the reference basin for 1984-2000.

\section{Discussion}

One decade following cessation of acid additions in Little Rock Lake, recovery of the zooplankton community was essentially complete. As others have reported for other lakes, biological recovery in LRL generally lagged behind chemical recovery (Arnott et al. 2001, Jeffries et al. 2003b, Skjelkvåle et al. 2003). In LRL, recovery of chemical parameters including major ions (Sampson 1999), minor metals (Brezonik et al. 2003), and nutrients (Sampson and Brezonik 2003) generally paralleled changes in $\mathrm{pH}$. In contrast, approximately $40 \%$ of zooplankton species exhibited a recovery lag (Table 1). In these cases, the $\mathrm{pH}$ had re- turned to a level higher than the $\mathrm{pH}$ level at which the original response to acidification had occurred, but biological recovery was delayed. Compared to most species with relatively short recovery lags, the $>4-y r$ delays in recovery of Leptodiaptomus minutus, Tropocyclops extensus, and Daphnia parvula were especially long. Nonetheless, even these recovery lags were relatively short in comparison to the longer lags observed in anthropogenically acidified lakes where recovery can be delayed for decades (Yan et al. 1996, Arnott et al. 2001). The relatively short recovery lags in LRL may be related to the experimental acidification procedure wherein $\mathrm{pH}$ was maintained at 4.7 for only 2 

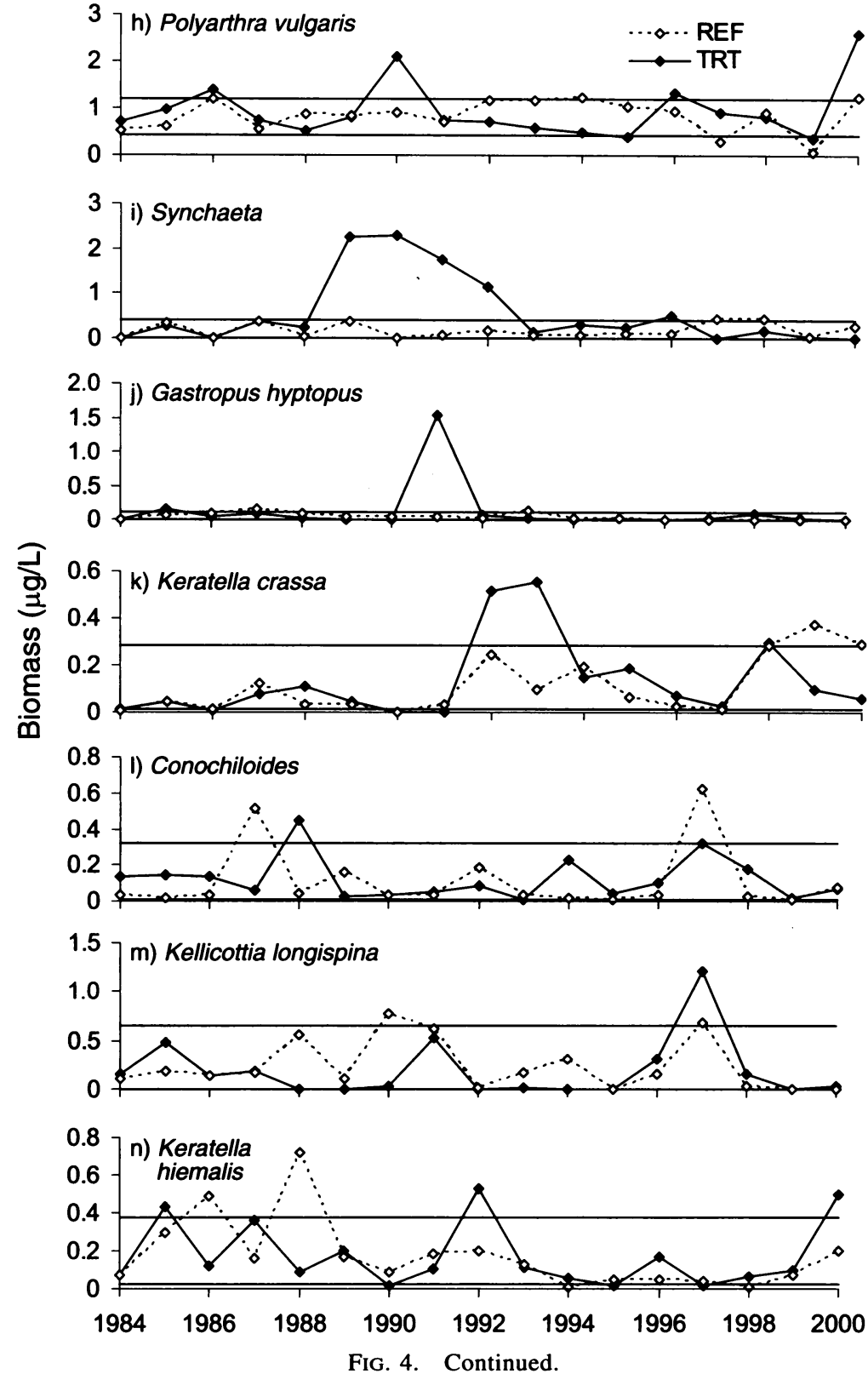

yr. Although some species decreased dramatically in LRL when conditions were most acidic, abundances were typically above the detection limit. It is logical that recovery from low abundance may proceed more rapidly than recovery from complete extirpation events such as those reported for anthropogenically acidified lakes. Vinebrook et al. (2003) report a similar result for epilithic algal assemblages in boreal lakes. Specifically, recovery of algal assemblages from a relatively short experimental acidification was more rapid than recovery from regional atmospheric acidification.

Determination of biological recovery depends to a large extent on the specific metric of community response chosen by the investigator in a particular study.
In general, we observed that highly aggregated community metrics (e.g., total zooplankton biomass) were less sensitive indicators of response and recovery from acidification than metrics that incorporated the identity of individual species (e.g., multivariate community analyses and biomass of individual species). For total zooplankton, rotifers, and copepods, aggregate biomass in the acidified basin deviated from the reference basin range for only 1-2 yr whereas the multivariate analyses for these groups suggested that the acidified basin communities departed from the range of variability in the reference basin for 7-9 yr. This pattern was not observed for cladocerans, however, in which aggregate biomass was more sensitive than community compo- 

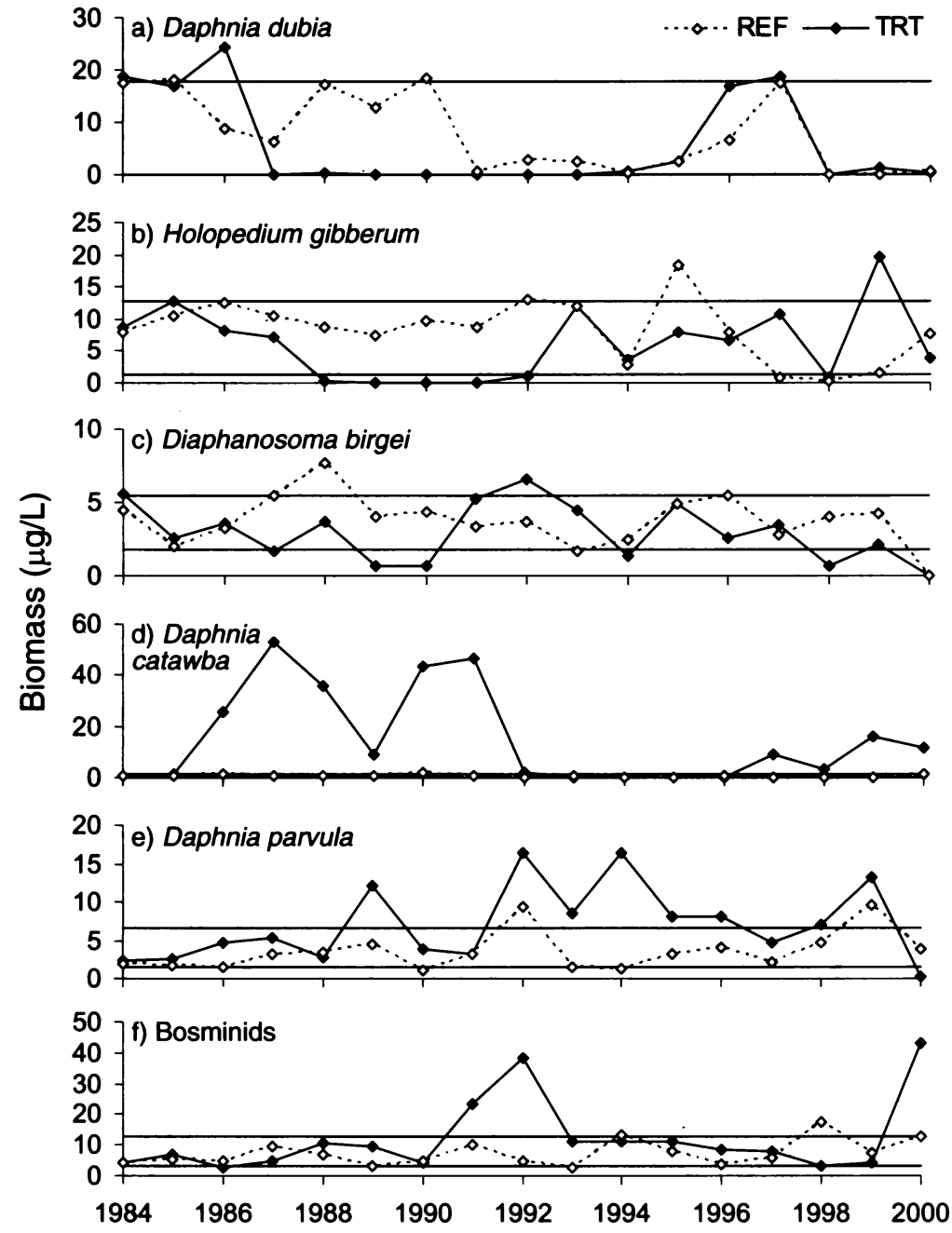

Fig. 5. Annual mean biomass of (a-e) cladoceran species and ( $f$ ) bosminids in the reference (REF) and treatment (TRT) basins of Little Rock Lake. Graphs are grouped by the nature of the response to acidification, with decreasing species first and increasing species second. Horizontal solid lines indicate 10th and 90th percentiles in the reference basin for 19842000.

sition. Cladoceran biomass in the acidified basin was out of the reference basin range for $8 \mathrm{yr}$ whereas the CA for community composition indicated significant species shifts in the acidified basin for only 5 yr (Figs. 2 and 3). Overall, we agree with Yan et al. (1996) that multivariate metrics that represent species abundances are most appropriate for analysis of recovery from perturbation. Important shifts in species composition can be masked in more aggregate variables like total zooplankton biomass due to processes such as compensatory dynamics (Frost et al. 1995, Fischer et al. 2001). Furthermore, many definitions of biological recovery emphasize the return of particular indicator species to the ecosystem (Gunn and Sandøy 2003).

Previous studies suggest that the rate of recovery can also vary substantially among taxonomic groups. For example, in Swan Lake, Ontario, recovery of the rotifer community proceeded quickly compared to crustacean recovery (Arnott et al. 2001). Examination of the CA for rotifers, cladocerans, and copepods reveals a different pattern in LRL. Cladoceran community composition appeared to have recovered in 1991 shortly after acid addition ended, whereas rotifer recovery was delayed until 1994 . Of the three taxonomic groups, copepod recovery proceeded most slowly and was delayed until 1997. Slow recovery of copepods was also reflected in the notably long mean recovery lags $(3.25 \mathrm{yr})$ compared to rotifers and cladocerans ( 0.78 and $1 \mathrm{yr}$, respectively). Differences in rates of recovery among taxonomic groups were probably not attributable to a lack of colonists as all of these groups produce resting stages that provide a source of internal colonists from the lake sediments (Hairston 1996). Furthermore, the relatively short duration of the most acidic conditions in LRL was probably not long enough to result in depletion of the egg bank. It is possible that 

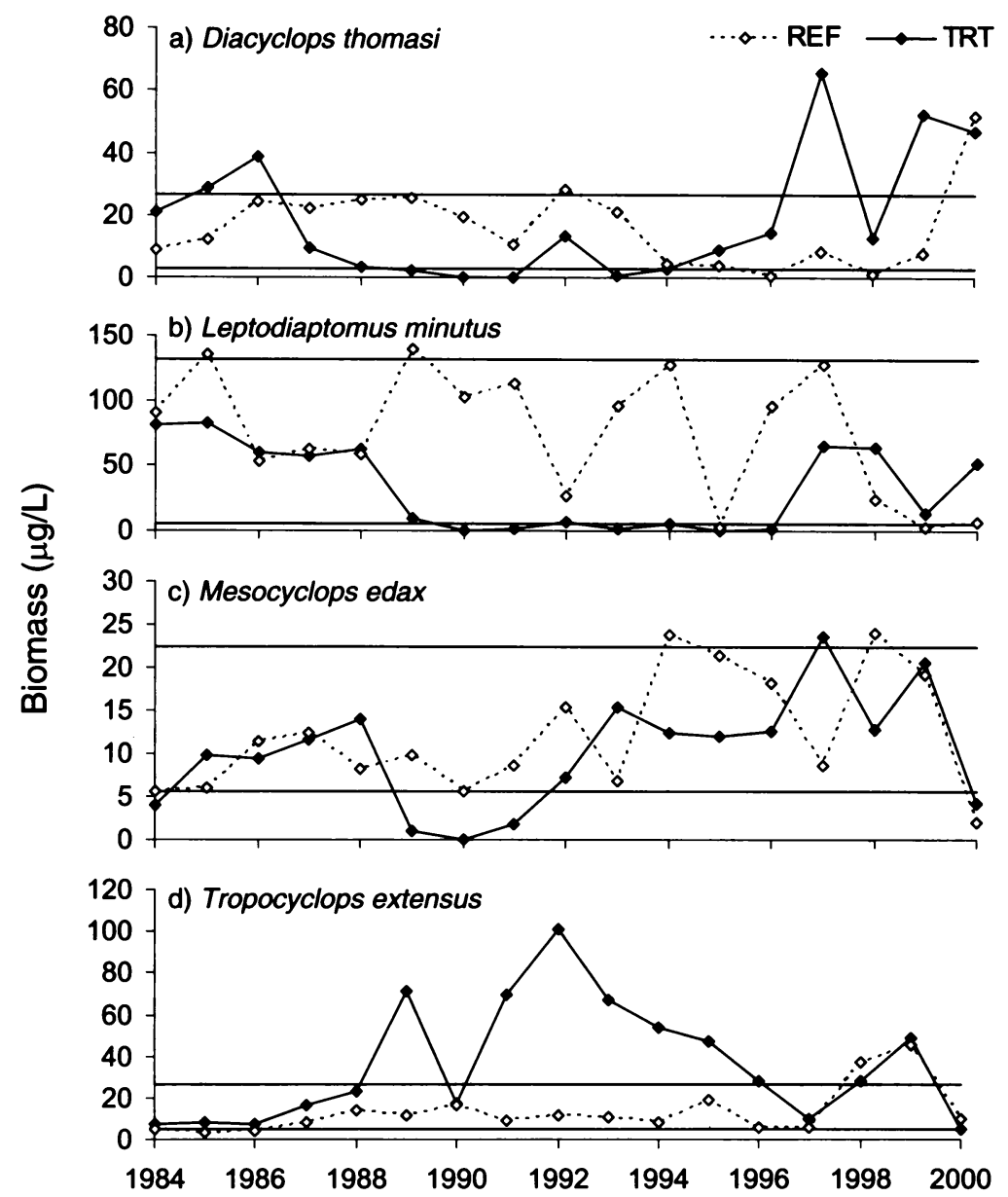

FIG. 6. Annual mean biomass of copepod species in the reference (REF) and treatment (TRT) basins of Little Rock Lake. Graphs are grouped by the nature of the response to acidification with decreasing species first and increasing species second. Horizontal solid lines indicate 10th and 90th percentiles in the reference basin for 1984-2000.

the long lag in recovery for copepods in LRL may have been related to their relatively long generation times, which are generally on the order of 2-3 wk or more in north temperate lakes (Williamson and Reid 2001). These long generation times may slow the rate of population responses to changes in environmental conditions for some species. For example, beginning in 1991, we observed a slow increase in biomass of Mesocyclops edax but this species did not fully recover to reference basin levels until the following year.

Others have proposed that delays in recovery such as those we observed in LRL may be attributable to "biological resistance" wherein establishment of viable populations of key acid-sensitive species following water quality improvements is prevented by other components of the community that thrived during acidification (Yan et al. 2003). For example, dense populations of invertebrate predators such as Chaoborus in fishless acidic lakes may impede recovery of some crustaceans (Holt and Yan 2003, Yan et al. 2003). It is unlikely that this invertebrate predator played a major role in LRL because Chaoborus abundance had declined to reference basin levels by 1992 . However, our analysis of the timing of recovery of acid chumps and acid champs does support the biological resistance hypothesis. We observed that the recovery rate for acid champs was faster than acid chumps (Fig. 8). Indeed, greater than $65 \%$ of all species in the acid champ category had declined to reference basin levels by 1993 , whereas only about $35 \%$ of species in the acid chump group had recovered by this time. Recovery of more than $75 \%$ of acid champs was observed in 1996, and full recovery of acid champs and chumps followed in 1997. This pattern may reflect biological resistance wherein some key strong interactors in the acid champ category limited population growth of acid chumps through interactions such as competition or predation.

The multivariate analyses of community responses provided a second line of evidence suggesting that biological resistance may play an important role in zooplankton recovery from acidification. The recovery pattern in the CA plots indicates that there was substantial 


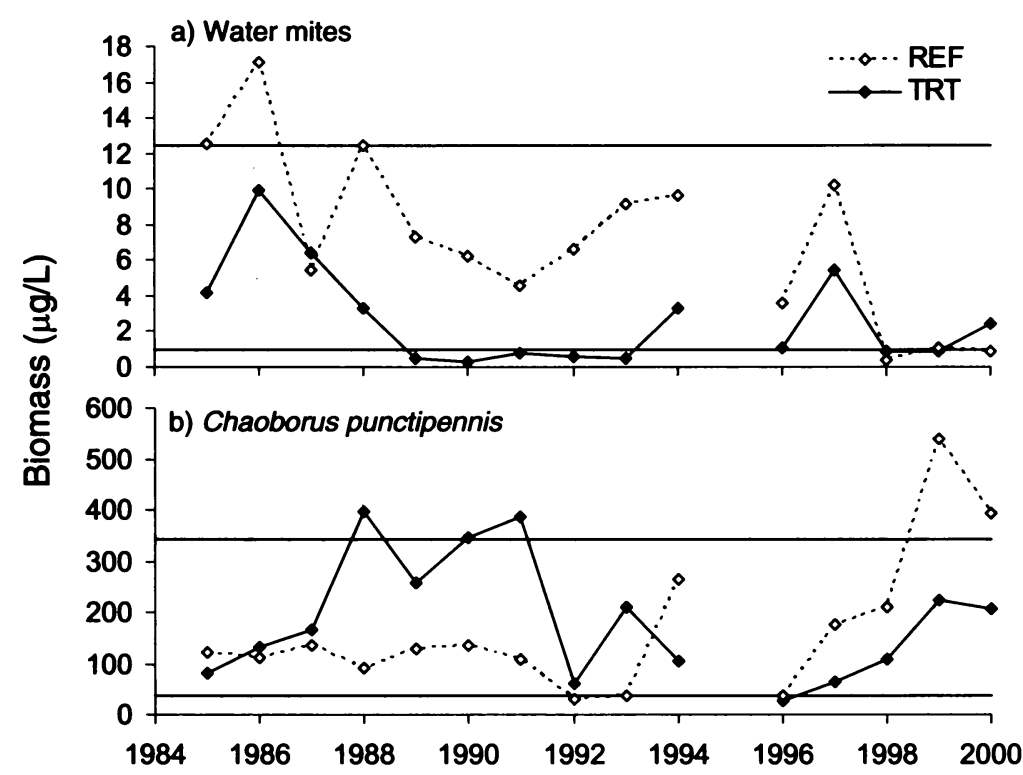

FIG. 7. Annual mean biomass of (a) water mites and (b) Chaoborus punctipennis in the reference (REF) and treatment (TRT) basins of Little Rock Lake. Horizontal solid lines indicate 10th and 90th percentiles in the reference basin for 19842000. Large predatory invertebrates were not sampled in 1995.

hysteresis in the recovery trajectory of zooplankton in LRL. Hysteresis is a term borrowed from physics indicating that a system does not simply retrace its path as driving variables change (Gutschick and BassiriRad 2003, Scheffer et al. 2004) and has been reported previously for algal responses to acidification (Vinebrooke et al. 2003). We observed hysteresis in zooplankton recovery from acidification in LRL because the community did not follow the same path during acidification and recovery (Fig. 3). This pattern was especially notable in the CAs for all species, rotifers, and copepods indicating that community composition traveled through novel configurations during recovery. We believe that this pattern may be indicative of biological resistance to recovery. For example, although species such as Daphnia parvula and Keratella crassa were not dominant species prior to or during acidification, they became prevalent during recovery. Recovery of some acid chumps (e.g., Daphnia dubia and Keratella cochlearis) may have been delayed by interactions with these potential competitors.

The biological resistance hypothesis suggests that processes governing community dynamics during recovery differ from processes that drive responses to acidification. For example, previous analyses of species interactions in LRL during acidification suggest that acid chumps are acid-sensitive, superior competitors that can suppress acid champs as long as $\mathrm{pH}$ is high (Fischer et al. 2001). Accordingly, one would expect that acid chumps would increase quickly following chemical recovery and subsequently cause a decline in acid champs. However, acid champs appeared to decline before acid chumps increased (Fig. 8a). It is possible that the early recovery of one or two key species in the acid chump category (e.g., Asplanchna or Mesocyclops edax) could cause dramatic declines in several acid champs that interact with these predators. It is also possible that small increases in acid chumps that fall short of complete recovery as we have defined it may nonetheless be sufficient to initiate decreases in some acid champs. Alternatively, our observation that declines in acid champs generally preceded increases in acid chumps may reflect shifts in competitive hierarchies during $\mathrm{pH}$ recovery as environmental conditions and relative abundances of chumps and champs change. For example, the outcome of competition may depend on the level of stress for acid chumps while $\mathrm{pH}$ is increasing. Unfortunately, it is impossible to identify mechanisms driving recovery dynamics without additional experiments that test the role of each recovering species.

Overall, zooplankton community recovery from experimental acidification in LRL generally reinforces the positive outlook for recovery reported for other acidified lakes (Arnott et al. 2001, Holt and Yan 2003). The LRL example differs from these previous studies of anthropogenically acidified lakes in several important ways. Increases in metals with acidification are a common feature in anthropogenically acidified lakes (LaZerte 1986) but were less dramatic in LRL (Brezonik et al. 2003). Lower concentrations of metals in LRL might have contributed to its rapid recovery from acidification. Pre-acidification data and closely matched reference systems have often been lacking for logistical and/or historical reasons in other studies. In LRL, we had the luxury of one year of pre-acidification data and parallel monitoring of the reference and acidified basins. We were somewhat surprised by the var- 
TABLE 1. For each response variable, the $\mathrm{pH}$ and year when the response variable in the acidified basin of Little Rock Lake, Wisconsin, USA, first left the region, defined by 10th and 90th percentiles of the reference basin, as well as the pH and year when the response variable recovered.

\begin{tabular}{|c|c|c|c|c|c|c|}
\hline \multirow[b]{2}{*}{ Response variable } & \multicolumn{2}{|c|}{$\mathrm{pH}$} & \multicolumn{2}{|c|}{ Year } & \multirow[b]{2}{*}{ Recovery lag } & \multirow{2}{*}{$\begin{array}{l}\text { Direction } \\
\text { of change }\end{array}$} \\
\hline & Response & Recovery & Response & Recovery & & \\
\hline $\mathrm{pH}$ & 5.61 & 6.03 & 1985 & 1996 & & D \\
\hline \multicolumn{7}{|l|}{ Totals } \\
\hline $\begin{array}{l}\text { Zooplankton } \\
\text { Rotifers } \\
\text { Cladocerans } \\
\text { Copepods }\end{array}$ & $\begin{array}{l}4.88 \\
5.22 \\
5.61 \\
4.88\end{array}$ & $\begin{array}{l}5.05 \\
5.31 \\
5.31 \\
5.05\end{array}$ & $\begin{array}{l}1990 \\
1992 \\
1985 \\
1990\end{array}$ & $\begin{array}{l}1991 \\
1993 \\
1993 \\
1991\end{array}$ & $\begin{array}{l}\mathbf{0} \\
\mathbf{0} \\
\mathbf{0} \\
\mathbf{0}\end{array}$ & $\begin{array}{l}\text { D } \\
\text { I } \\
\text { I } \\
\text { D }\end{array}$ \\
\hline \multicolumn{7}{|l|}{ Rotifers } \\
\hline $\begin{array}{l}\text { Asplanchna (Aspl) } \\
\text { Conochilus (Conoc) } \\
\text { Keratella cochlearis (Keraco) } \\
\text { Trichocerca cylindrical (Tric) } \\
\text { Gastropus stylifer (Gasts) } \\
\text { Keratella taurocephala (Kerat) } \\
\text { Polyarthra remata (Polyr) } \\
\text { Polyarthra vulgaris (Polyv) } \\
\text { Synchaeta (Sync) } \\
\text { Gastropus hyptopus (Gasth) } \\
\text { Keratella crassa (Keracr) } \\
\text { Conochiloides (Conod) } \\
\text { Kellicottia longispina (Kell) } \\
\text { Keratella hiemalis (Kerah) }\end{array}$ & $\begin{array}{l}5.61 \\
4.83 \\
5.29 \\
5.29 \\
5.29 \\
5.29 \\
4.83 \\
4.88 \\
4.83 \\
5.05 \\
4.88 \\
\text { NR } \\
\text { NR } \\
\text { NR }\end{array}$ & $\begin{array}{l}5.22 \\
5.50 \\
5.70 \\
5.50 \\
5.05 \\
5.31 \\
6.03 \\
5.05 \\
5.31 \\
5.22 \\
5.55 \\
\text { NR } \\
\text { NR } \\
\text { NR }\end{array}$ & $\begin{array}{l}1985 \\
1989 \\
1987 \\
1987 \\
1987 \\
1987 \\
1989 \\
1990 \\
1989 \\
1991 \\
1990 \\
\text { NR } \\
\text { NR } \\
\text { NR }\end{array}$ & $\begin{array}{r}1992 \\
1994 \\
1995 \\
1994 \\
1991 \\
1993 \\
1996 \\
1991 \\
1993 \\
1992 \\
1994 \\
\text { NR } \\
\text { NR } \\
\text { NR }\end{array}$ & $\begin{array}{c}0 \\
2 \\
0 \\
0 \\
0 \\
0 \\
4 \\
0 \\
1 \\
\text { NA } \\
3 \\
\text { NA } \\
\text { NA } \\
\text { NA }\end{array}$ & $\begin{array}{l}\text { D } \\
\text { D } \\
\text { D } \\
\text { D } \\
\text { I } \\
\text { I } \\
\text { I } \\
\text { I } \\
\text { I } \\
\text { I }_{\mathbf{r}} \\
\text { D/I } \\
\text { NA } \\
\text { NA } \\
\text { NA }\end{array}$ \\
\hline \multicolumn{7}{|l|}{ Cladocerans } \\
\hline $\begin{array}{l}\text { Daphnia dubia (Daphd) } \\
\text { Holopedium gibberum (Holo) } \\
\text { Diaphanosoma birgei (Diap) } \\
\text { Daphnia catawba (Daphc) } \\
\text { Daphnia parvula (Daphp) } \\
\text { Bosminids (Bosm) }\end{array}$ & $\begin{array}{l}5.29 \\
5.13 \\
4.83 \\
5.59 \\
4.83 \\
5.05\end{array}$ & $\begin{array}{l}5.50 \\
5.31 \\
5.05 \\
5.22 \\
6.15 \\
5.31\end{array}$ & $\begin{array}{l}1987 \\
1988 \\
1989 \\
1986 \\
1989 \\
1991\end{array}$ & $\begin{array}{l}1994 \\
1993 \\
1991 \\
1992 \dagger \\
1997 \\
1993\end{array}$ & $\begin{array}{c}0 \\
0 \\
0 \\
0 \\
5 \\
\text { NA }\end{array}$ & $\begin{array}{l}\text { D } \\
\text { D } \\
D \\
\text { I } \\
\text { I } \\
I_{r}\end{array}$ \\
\hline \multicolumn{7}{|l|}{ Copepods } \\
\hline $\begin{array}{l}\text { Diacyclops thomasi (Diac) } \\
\text { Leptodiaptomus minutus (Lept) } \\
\text { Mesocyclops edax (Meso) } \\
\text { Tropocyclops extensus (Trop) }\end{array}$ & $\begin{array}{l}4.83 \\
4.88 \\
4.83 \\
4.83\end{array}$ & $\begin{array}{l}5.50 \\
6.15 \\
5.22 \\
6.15\end{array}$ & $\begin{array}{l}1989 \\
1990 \\
1989 \\
1989\end{array}$ & $\begin{array}{l}1994 \\
1997 \\
1992 \\
1997\end{array}$ & $\begin{array}{l}2 \\
6 \\
0 \\
5\end{array}$ & $\begin{array}{l}\text { D } \\
\text { D } \\
\text { D } \\
\text { I }\end{array}$ \\
\hline \multicolumn{7}{|l|}{ Large predatory invertebrates } \\
\hline $\begin{array}{l}\text { Mites } \\
\text { Chaoborus punctipennis }\end{array}$ & $\begin{array}{l}4.83 \\
5.13\end{array}$ & $\begin{array}{l}5.50 \\
5.22\end{array}$ & $\begin{array}{l}1989 \\
1988\end{array}$ & $\begin{array}{l}1994 \\
1992\end{array}$ & $\begin{array}{l}2 \\
0\end{array}$ & D \\
\hline
\end{tabular}

Notes: A subjective approach guided by statistical principle and intuition was used to judge recovery. Specifically, we concluded that a species had recovered from acidification once its annual mean biomass was consistently within the range of variability defined by the 10th and 90th percentiles of the reference basin data (see Methods: Data analysis for additional details). Species that never left the reference region are labeled NR. Lag was defined as the time delay between chemical recovery (based on return to the mean annual $\mathrm{pH}$ value in the year before the species responded to acidification) and biomass recovery of each taxon. Species that did not respond during the acidification phase (1985-1990) are denoted NA. Direction of change refers to whether the taxa increased (I) or decreased (D). $I_{r}$ indicates that the taxon increased early in the recovery period. Codes in parentheses after species names are used to denote species in Fig. 3.

$\dagger$ Note that Daphnia catawba increased above the 90th percentile for the reference basin in 1997-2000.

iability of the reference basin during our study period. In many ways, the reference basin was a moving target and some changes in community composition in the reference basin were nearly as dramatic as the species shifts in the treatment basin (see Fig. 3e). The variability in the reference system broadened the recovery target in LRL and provides a reminder that recovery cannot always be defined as an exact reconstruction of historical communities.

While the recovery of zooplankton in LRL and other lakes paints a hopeful picture for recovery from acidification, it is important to point out that recovery has been delayed for decades or indefinitely in other systems (Yan et al. 1996, Arnott et al. 2001). Other authors have attributed differences in recovery rates to duration and severity of acidification and suggest that systems subjected to severe damage for extended time periods may have limited capacity for recovery (Yan et al. 1996). We believe that the recovery of zooplankton in LRL underscores this point by providing an example of rapid recovery from a relatively mild and short acidification experiment. Overall, there appears to be a favorable outlook for ecological recovery from perturbations such as acidification when remediation policies 

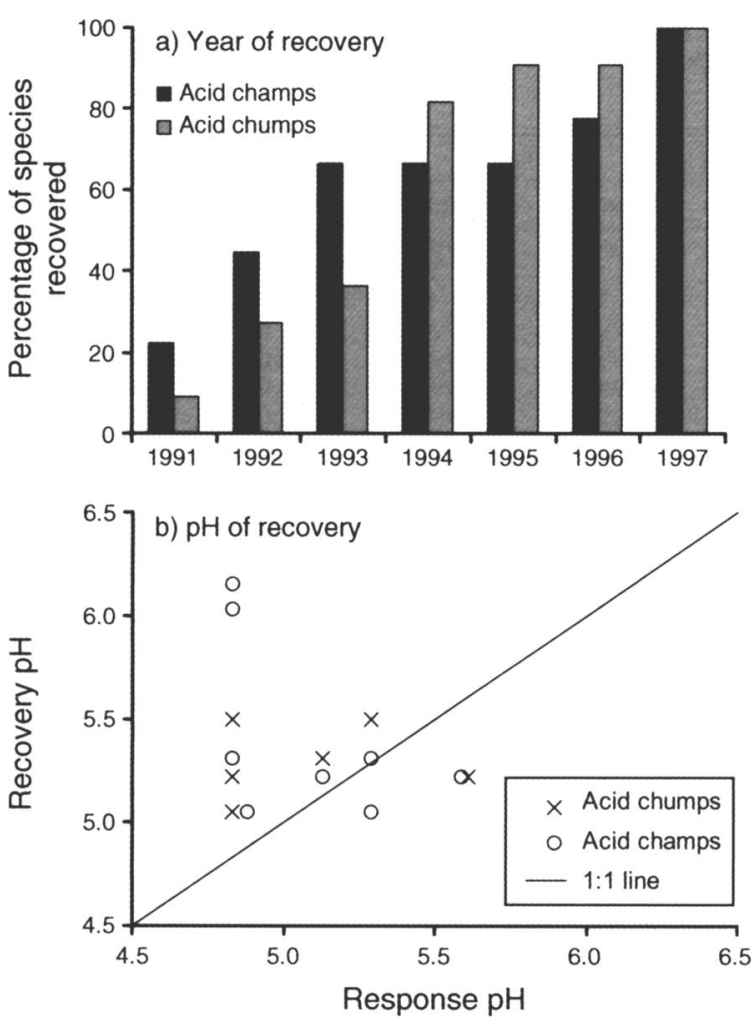

FIG. 8. (a) Cumulative percentage of species that had recovered in each year of the recovery phase. (b) Relationship between the $\mathrm{pH}$ at which a species responded during the acidification period and the $\mathrm{pH}$ at which it recovered. Points above the $1: 1$ line indicate species that recovered at higher $\mathrm{pH}$ than they responded to during the acidification phase. We used a subjective approach guided by statistical principle and intuition to judge recovery. Specifically, we concluded that a species had recovered from acidification once its annual mean biomass was consistently within the range of variability defined by the 10th and 90th percentiles of the reference basin data (see Methods: Data analysis for additional details on our approach). "Acid champs" are species that were favored by acidification and increased, whereas species in the "acid chumps" category declined during the acidification phase of the experiment.

are implemented in a timely fashion; however, delays in implementing policy changes may exceed the capacity for ecosystem resilience.

\section{ACKNOWLEDGMENTS}

The Little Rock Experimental Acidification Project has been supported by funding from the National Science Foundation, the U.S. Environmental Protection Agency, the U.S. Geological Survey, and the state of Wisconsin. It has also received logistic assistance from the North Temperate Lakes Long Term Ecological Research Program. Comments from Anthony R. Ives, Timothy K. Kratz, Mark H. Olson, and two anonymous reviewers significantly improved the manuscript.

\section{Literature Cited}

Arnott, S. E., N. Yan, W. Keller, and K. Nicholls. 2001. The influence of drought-induced acidification on the recovery of plankton in Swan Lake (Canada). Ecological Applications 11:747-763.
Brezonik, P. L., C. E. Mach, and C. J. Sampson. 2003. Geochemical controls for $\mathrm{Al}, \mathrm{Fe}, \mathrm{Mn}, \mathrm{Cd}, \mathrm{Cu}, \mathrm{Pb}$, and $\mathrm{Zn}$ during experimental acidification and recovery of Little Rock Lake, WI, USA. Biogeochemistry 62:119-143.

Brezonik, P. L., et al. 1993. Experimental acidification of Little Rock Lake, Wisconsin: chemical and biological changes over the pH range 6.1 to 4.7. Canadian Journal of Fisheries and Aquatic Sciences 50:1101-1121.

Culver, D. A., M. M. Boucherle, D. J. Bean, and J. W. Fletcher. 1985. Biomass of freshwater crustacean zooplankton from length-weight regressions. Canadian Journal of Fisheries and Aquatic Sciences 42:1380-1390.

Dixit, S. S., A. S. Smol, and J. P. Smol. 2002. Diatom and chrysophyte functions and inferences of post-industrial acidification and recent recovery trends in Kilarney lakes (Ontario, Canada). Journal of Paleolimnology 27:79-96.

Driscoll, C. T., K. M. Driscoll, K. M. Roy, and M. J. Mitchell. 2003. Chemical response of lakes in the Adirondack $\mathrm{Re}$ gion of New York to declines in acidic deposition. Environmental Science and Technology 37:2036-2042.

Driscoll, C. T., G. B. Lawrence, A. J. Bulger, T. J. Butler, C. S. Cronan, C. Eagar, K. F. Lambert, G. E. Likens, J. L. Stoddard, and K. C. Weathers. 2001. Acidic deposition in the northeastern United States: sources and inputs, ecosystem effects, and management strategies. Bioscience 51: 180-198.

Evans, C. D., J. M. Cullen, C. Alewell, J. Kopacek, A. Marchetto, F. Moldan, A. Prechtel, M. Rogora, J. Vesely, and R. Wright. 2001. Recovery from acidification in European surface waters. Hydrology and Earth System Sciences 5: 283-297.

Evans, C. D., and D. T. Monteith. 2001. Chemical trends at lakes and streams in the UK Acid Waters Monitoring Network, 1988-2000: evidence for recent recovery at a national scale. Hydrology and Earth System Sciences 5:351366.

Findlay, D. L. 2003. Response of phytoplankton communities to acidification and recovery in Killarney Park and the Experimental Lake Area, Ontario. Ambio 32:190-195.

Fischer, J. M. 1994. Stage-structured dynamics of an invertebrate predator. Thesis. University of Wisconsin, Madison, Wisconsin, USA.

Fischer, J. M., T. M. Frost, and A. R. Ives. 2001. Compensatory dynamics in zooplankton community responses to acidification: measurement and mechanisms. Ecological Applications 11:1060-1072.

Forsius, M., J. Vuorenmaa, J. Mannio, and S. Syri. 2003. Recovery from acidification of Finnish lakes: regional patterns and relations to emission reduction policy. Science of the Total Environment 310:121-132.

Frost, T. M., S. R. Carpenter, A. R. Ives, and T. K. Kratz. 1995. Species compensation and complementarity in ecosystem function. Pages 224-239 in C. G. Jones and J. H. Lawton, editors. Linking species and ecosystems. Chapman and Hall, New York, New York, USA.

Frost, T. M., and P. M. Montz. 1988. Early zooplankton response to experimental acidification of Little Rock Lake, Wisconsin, USA. Verhandlungen Internationale Vereinigung für theoretische und angewandte Limnologie 23: 2279-2285.

Frost, T. M., P. K. Montz, and T. K. Kratz. 1998. Zooplankton community responses during recovery from acidification in Little Rock Lake, Wisconsin. Restoration Ecology 6:336342.

Frost, T. M., et al. 1999. Multiple stresses from a single agent: diverse responses to the experimental acidification of Little Rock Lake, Wisconsin. Limnology and Oceanography 44:784-794.

Gotelli, N. J., and A. M. Ellison. 2004. A primer of ecological statistics. Sinauer, Sunderland, Massachusetts, USA. 
Gunn, J. M., and S. Sandøy. 2003. Introduction to the Ambio special issues on biological recovery from acidification: northern lakes recovery study. Ambio 32:162-164.

Gutschick, V. P., and H. BassiriRad. 2003. Extreme events as shaping physiology, ecology, and evolution of plants: toward a unified definition and evaluation of their consequences. New Phytologist 160:21-42.

Hairston, N. G., Jr. 1996. Zooplankton egg banks as biotic reservoirs in changing environments. Limnology and Oceanography 41:1087-1092.

Hawkins, B. E., and M. S. Evans. 1979. Seasonal cycles of zooplankton biomass in southeastern Lake Michigan. Journal of Great Lakes Research 5:256-263.

Henriksen, A., P. J. Dillon, and J. Aherne. 2002. Critical loads of acidity for surface waters in south-central Ontario, Canada: regional application of the steady-state water chemistry (SSWC) model. Canadian Journal of Fisheries and Aquatic Sciences 59:1287-1295.

Holt, C., and N. D. Yan. 2003. Recovery of crustacean zooplankton communities from acidification in Killarney Park, Ontario, 1971-2000: pH 6 as a recovery goal. Ambio 32: 203-207.

Jackson, D. A. 1993. Multivariate analysis of benthic invertebrate communities: the implication of choosing particular data standardizations, measures of association, and ordination methods. Hydrobiologia 268:9-26.

Jeffries, D. S., T. G. Brydges, P. J. Dillon, and W. Keller. 2003a. Monitoring the results of Canada/USA acid rain control programs: some lake responses. Environmental Monitoring and Assessment 88:3-19.

Jeffries, D. S., T. A. Clair, S. Couture, P. J. Dillon, J. Dupont, W. Keller, D. K. McNicol, M. A. Turner, R. Vet, and R. Weeber. $2003 \mathrm{~b}$. Assessing recovery of lakes in southeastern Canada from the effects of acidic deposition. Ambio 32:176-182.

Keller, W., J. H. Heneberry, and S. S. Dixit. 2003. Decreased acid deposition and the chemical recovery of Killarney, Ontario, lakes. Ambio 32:183-189.

Keller, W., and N. D. Yan. 1998. Biological recovery from lake acidification: zooplankton communities as a model of patterns and processes. Restoration Ecology 6:364-375.

Keller, W., N. D. Yan, K. M. Somers, and J. H. Heneberry. 2002. Crustacean zooplankton communities in lakes recovering from acidification. Canadian Journal of Fisheries and Aquatic Sciences 59:726-735.

Lawrence, S. G., D. F. Malley, W. J. Findlay, M. A. MacIver, and I. L. Delbaere. 1987. Methods for estimating dry weight of freshwater planktonic crustaceans from measures of length and shape. Canadian Journal of Fisheries and Aquatic Sciences 44:264-274.

LaZerte, B. 1986. Metals and acidification: an overview. Water, Air and Soil Pollution 31:569-576.

Locke, A., and W. G. Sprules. 1994. Effects of lake acidification and recovery on the stability of zooplankton food webs. Ecology 75:498-506.

Meyer, E. 1989. The relationship between body length parameters and dry mass in running water invertebrates. Archiv für Hydrobiologie 117:191-203.

Mittelbach, G. G., A. M. Turner, D. J. Hall, and J. E. Rettig. 1995. Perturbation and resilience: a long-term, whole-lake study of predator extinction and reintroduction. Ecology 76:2347-2360.

Nilssen, J. P., and S. B. Waervagen. 2002. Recent re-establishment of the key species Daphnia longispina and cladoceran community changes following chemical recovery in a strongly acid-stressed region in southern Norway. Archiv für Hydrobiologie 153:557-580.

Pace, M. L., and J. D. Orcutt, Jr. 1981. The relative importance of protozoa, rotifers, and crustaceans in a freshwater zooplankton community. Limnology and Oceanography 26: 822-830.
Parr, T. W., A. R. J. Sier, R. W. Battarbee, A. Mackay, and J. Burgess. 2003. Detecting environmental change: science and society-perspectives on long-term research and monitoring in the 21 st century. Science of the Total Environment 310:1-8.

Ruttner-Kolisko, A. 1977. Suggestions for biomass calculation of plankton rotifers. Archiv für Hydrobiologie, Beiheft, Ergebnisse der Limnologie 8:71-76.

Sampson, C. J. 1999. Aquatic chemistry of Little Rock Lake, Wisconsin, during acidification and recovery. Dissertation. University of Minnesota, Minneapolis, Minnesota, USA.

Sampson, C. J., and P. L. Brezonik. 2003. Responses of nutrients to experimental acidification in Little Rock Lake, U.S.A. Water, Air and Soil Pollution 142:1-19.

SAS Institute. 1996. SAS software. Version 6.12. SAS Institute, Cary, North Carolina, USA.

Scheffer, M., S. Carpenter, J. A. Foley, C. Folke, and B. Walker. 2004. Catastrophic shifts in ecosystems. Nature 413:591-596.

Sierszen, M. E., and T. M. Frost. 1993. Response of predatory zooplankton populations to the experimental acidification of Little Rock Lake, Wisconsin. Journal of Plankton Research 15:553-562.

Skjelkvåle, B. L., C. Evans, T. Larssen, A. Hindar, and G. G. Raddum. 2003. Recovery from acidification in European surface waters: a view to the future. Ambio 32:170-175.

Skjelkvåle, B. L., J. Mannio, A. Wilander, and T. Andersen. 2001. Recovery from acidification of lakes in Finland, Norway and Sweden 1990-1999. Hydrology and Earth System Sciences 5:327-337.

Snucins, E. 2003. Recolonization of acid-damaged lakes by the benthic invertebrates Stenacron interpunctatum, Stenonema femoratum, and Hyalella azteca. Ambio 32:225229.

Stoddard, J. L., et al. 1999. Regional trends in aquatic recovery from acidification in North America and Europe. Nature 401:575-578.

Vinebrooke, R. D., M. D. Graham, D. L. Findlay, and M. A. Turner. 2003. Resilience of epilithic algal assemblages in atmospherically and experimentally acidified boreal lakes. Ambio 32:196-202.

Vrba, J., J. Kopacek, J. Fott, L. Kohout, L. Nedbalova, M. Prazakova, T. Soldan, and J. Schaumburg. 2003. Long-term studies (1871-2000) on acidification and recovery of lakes in the Bohemian Forest (central Europe). Science of the Total Environment 310:73-85.

Waeervagen, S. B., and J. P. Nilssen. 2003. Major changes in pelagic rotifers during natural and forced recovery from acidification. Hydrobiologia 499:63-82.

Walseng, B., G. Halvorsen, and S. E. Sloreid. 2001. Littoral microcrustaceans (Cladocera and Copepoda) as indices of recovery of a limed water system. Hydrobiologia 450:159_ 172.

Williamson, C. E., and J. W. Reid. 2001. Copepoda. Pages 915-954 in J. H. Thorp and A. P. Covich, editors. Ecology and classification of North American freshwater invertebrates. Second edition. Academic Press, San Diego, California, USA.

Yan, N. D., W. Keller, K. M. Somers, T. W. Pawson, and R. E. Girard. 1996. Recovery of crustacean zooplankton communities from acid and metal contamination: comparing manipulated and reference lakes. Canadian Journal of Fisheries and Aquatic Sciences 53:1301-1327.

Yan, N. D., B. Leung, W. Keller, S. E. Arnott, J. M. Gunn, and G. G. Raddum. 2003. Developing conceptual frameworks for the recovery of aquatic biota from acidification. Ambio 32:165-169.

Yan, N. D., and G. L. Mackie. 1987. Improved estimation of the dry weight of Holopedium gibberum (Crustacea, Cladocera) using clutch size, a body fat index, and lake water total phosphorus concentration. Canadian Journal of Fisheries and Aquatic Sciences 44:382-389. 